University of Nebraska - Lincoln

DigitalCommons@University of Nebraska - Lincoln

Publications of the University of Nebraska

Public Policy Center

Public Policy Center, University of Nebraska

2013

\title{
Risk and Protective Factors for Recidivism Among Juveniles Who Have Offended Sexually
}

\author{
Andrew Spice \\ Simon Fraser University \\ Jodi L. Viljoen \\ AndrewSpice \\ Natasha Elkovitch \\ University of Nebraska - Lincoln, nelkovitch@huskers.unl.edu \\ Mario J. Scalora \\ University of Nebraska-Lincoln, mscalora1@unl.edu \\ Daniel Lee Ullman \\ University of Nebraska - Lincoln
}

Follow this and additional works at: https://digitalcommons.unl.edu/publicpolicypublications

Part of the Other Public Affairs, Public Policy and Public Administration Commons, Other Social and Behavioral Sciences Commons, Public Affairs Commons, Public Policy Commons, and the Social Policy Commons

Spice, Andrew; Viljoen, Jodi L.; Elkovitch, Natasha; Scalora, Mario J.; and Ullman, Daniel Lee, "Risk and Protective Factors for Recidivism Among Juveniles Who Have Offended Sexually" (2013). Publications of the University of Nebraska Public Policy Center. 192.

https://digitalcommons.unl.edu/publicpolicypublications/192

This Article is brought to you for free and open access by the Public Policy Center, University of Nebraska at DigitalCommons@University of Nebraska - Lincoln. It has been accepted for inclusion in Publications of the University of Nebraska Public Policy Center by an authorized administrator of DigitalCommons@University of Nebraska - Lincoln. 
Risk and Protective Factors for Recidivism Among Juveniles Who Have Offended Sexually

Andrew Spice Jodi L. Viljoen

Simon Fraser University

Natasha Elkovitch Latzmann Mario J. Scalora

University of Nebraska-Lincoln

Daniel Ullman

Lincoln Regional Center

Sexual Abuse: A Journal of Research and Treatment

DOI: https://doi.org/10.1177/1079063212459086 


\begin{abstract}
Literature on risk factors for recidivism among juveniles who have sexually offended (JSOs) is limited. In addition, there have been no studies published concerning protective factors among this population. The purpose of this study was to examine the relationship of risk and protective factors to sexual and nonsexual recidivism among a sample of 193 male JSOs (mean age $=15.26$ ). Youth were followed for an average of 7.24 years following discharge from a residential sex offender treatment program. The risk factor opportunities to reoffend, as coded based on the ERASOR (Worling \& Curwen, 2001), was associated with sexual recidivism. Several risk factors (e.g., prior offending; peer delinquency) were associated with nonsexual recidivism. No protective factors examined were associated with sexual recidivism, although strong attachments and bonds as measured by the SAVRY (Borum et al., 2006) was negatively related to nonsexual recidivism. These findings indicate that risk factors for nonsexual recidivism may be consistent across both general adolescent offender populations and JSOs, but that there may be distinct protective factors that apply to sexual recidivism among JSOs. Results also indicate important needs for further research on risk factors, protective factors, and risk management strategies for JSOs.
\end{abstract}


Risk and Protective Factors for Recidivism

Among Juveniles Who Have Offended Sexually

The past two decades have witnessed escalating public concern about risk for recidivism among juveniles who have committed sexual offenses (JSOs) (Worling \& Långström, 2006). These concerns have been expressed in various forms, including that overall rates of juvenile sexual offending are at an all-time high (Zimring, 2004) and that JSOs are severe delinquents who resemble predatory adult sex offenders (Caldwell, 2010). Despite the paucity of empirical evidence supporting such beliefs (Letourneau \& Miner, 2005), alarm about high rates of sexual recidivism has been reflected in the enactment of increasingly punitive American laws for the management of juvenile sex offending. These laws include means for involuntary commitment to psychiatric hospitals (Caldwell, 2007) and the extension of public sex offender registration and notification requirements to juveniles (Trivits \& Reppucci, 2002). After the enactment of the Adam Walsh Act, these registration and notification procedures will require many JSOs to remain on a sex offender registry for the rest of their lives (Caldwell, Ziemke, \& Vitacco, 2008).

The gravity of these potential consequences for so-called "high-risk" JSOs underscores the importance of accurately evaluating their likelihood of reoffending, which is a task that often falls to mental health professionals (e.g., Borum \& Verhaagen, 2006). Clinicians, however, face a number of considerable obstacles in this endeavor. Chief among these is the fact that adolescents are in a state of constant change and development, which has led researchers to liken them to "moving targets" (Grisso, 1998). There is also controversy regarding whether JSOs share features that make them unique among adolescent offenders, such as early victimization (Knight \& Sims-Knight, 2003) or early exposure to deviant sexuality (Burton, 2003), although recent evidence (Seto \& Lalumière, 2010) indicates that factors such as atypical sexual interests and sexual abuse history may differentiate adolescents who have committed sexual versus nonsexual offenses. However, it remains unknown as to whether the "life-course persistent vs. adolescence-limited” typology can be meaningfully applied to JSOs in order to distinguish youths at continued risk for sexual recidivism from those who are likely to desist upon reaching adulthood (Moffitt, 1993).

The available research on patterns of offending among JSOs offers little guidance to clinicians in regard to these challenges. Meta-analytic findings regarding base rates of sexual reoffending (McCann \& Lussier, 2008), for example, indicate recidivism rates ranging from $1.6 \%$ to $29.9 \%$. These varying findings make it difficult to ascertain whether sexual offences committed in adolescence are rare instances or part of a pattern of behavior that is likely to recur. Further, results of a more recent meta-analysis (Caldwell, 2010) indicated that recidivism rates among JSOs were $7.08 \%$ for sexual offences and $43.4 \%$ for nonsexual offences, suggesting that JSOs may be far more likely to reoffend nonsexually than sexually. Similar results were obtained in an individual study in a non-Western setting (Chu \& Thomas, 2010); the researchers found that JSOs recidivated sexually from $9.9 \%$ to $14.3 \%$ and nonsexually from $16.9 \%$ to $37.7 \%$. Hence, 
due to low base rates, sexual recidivism may be more difficult to predict than nonsexual recidivism.

\section{Risk Factors for Recidivism}

To help determine which youth may be at higher risk for sexually reoffending, further knowledge is needed on risk factors for recidivism in this population. Although some studies have been carried out to address this gap in knowledge, this body of literature is characterized by a number of methodological limitations. First, follow-up periods in early studies have tended to be less than three years (e.g., Kahn \& Chambers, 1991; Prentky et al., 2000), and others include sample sizes that are less than 100 (e.g., Boyd, 1994; Miner, 2002). Although more recent studies have been designed to include longer follow-up periods (e.g., Viljoen et al., 2009; Worling et al., 2010), it may be the case that youth are not followed long enough for recidivism to occur or that statistical power is insufficient to detect significant effects. Secondly, the reliability of methods for coding risk factors is often unreported (e.g., Allan et al., 2003; Smith \& Monastersky, 1986), which is problematic given the high degree of clinical inference required to assess potential risk factors such as internal motivation to change (e.g., Prentky \& Righthand, 2003). Finally, and most critically, the risk factors selected for analysis have varied widely. For example, although some studies have included factors such as empathy and the youth's history of being sexually abused (e.g., Kahn \& Chambers, 2001; Smith \& Monastersky, 1986), such factors are not addressed in other studies (e.g., Allen et al., 2003). Indeed, despite that some studies appear to include risk factors based on theoretical frameworks and/or previous empirical findings (e.g., Långström, 2002), others have included risk factors based on their availability in justice databases (e.g., Nisbet et al., 2004) or according to researchers' hypotheses (e.g., Rasmussen, 1999).

Given the above problems, it is perhaps not surprising that findings from these individual studies are inconsistent. For example, although the youth's history of having been sexually abused was a significant predictor by Smith and Monastersky (1986), Rasmussen (1999) did not find that this factor was a predictor. These issues point to a need for a clear and systematic rationale for the selection of risk factors. Adding further complexity to this challenge, recent recommendations have emphasized the importance of not only the empirical correlates of risk factors but also their idiographic meaning in the context of the individual offender (Mann et al., 2010).

Given the fractured nature of these studies on risk factors for sexual recidivism among JSOs, several attempts have been made to synthesize the literature via metaanalysis. An initial step in this area was taken by Cottle, Lee, and Heilbrun (2001), who meta-analyzed studies on nonsexual reoffending among adolescent offenders in general. Cottle et al. identified several factors that were significant predictors of nonsexual recidivism, such as age at first contact with authorities and age at first commission of an offence. However, these researchers found that there were too few studies to examine risk factors for sexual reoffending. This problem was addressed in a later meta-analysis (Heilbrun, Lee, \& Cottle, 2005) including a larger number of studies ( $N=9$ ), which revealed that younger age, commission of noncontact offenses, and having an acquaintance victim were associated with a greater likelihood of sexual recidivism. These 
latter findings suggested that assessment of JSOs' risk of reoffending sexually could be assisted by the identification of particular risk factors specific to the youth and their offence. Similar results were obtained by Hanson and Morton-Bourgon (2005) in a metaanalysis including both adult and adolescent offenders. These authors found that sexual deviance and antisocial orientation were both predictive of sexual recidivism.

In a subsequent effort to identify such risk factors, Worling and Långström (2006) reviewed the literature and classified risk factors qualitatively as supported, promising, possible, or unlikely according to their degree of empirical support. Worling and Långström defined supported factors (e.g., deviant sexual interests) as those that were upheld by at least two independent empirical studies and that were not based on contradictory evidence, promising factors (e.g., attitudes supportive of sexual offending) as those upheld by at least one study and that were noted by authors of juvenile risk assessment instruments, possible factors (e.g., high-stress family environment) as those that had been identified in the literature by some authors, and unlikely factors (e.g., lack of victim empathy) as those that were based on contradictory empirical evidence.

Worling and Långström’s (2006) review identified a large number of potential risk factors for sexual recidivism among JSOs. Also, by highlighting the sheer quantity of risk factors based only on adult literature, contradictory evidence, or negative empirical evidence, Worling and Långström highlighted a critical need for further studies in this area. This need was made even more salient by the authors' observation that several juvenile risk assessment measures include risk factors with absent or negative empirical support.

The most recent attempt to integrate the literature on risk factors for juvenile sexual reoffending is a meta-analysis by McCann and Lussier (2008) that included 18 studies. Consistent with Worling and Långström’s (2006) review, McCann and Lussier found that deviant sexual interests, a history of sexual offences, and having a stranger victim were predictive of recidivism. However, several factors noted by Worling and Långström as being unlikely or possible were also found to be predictive, including previous nonsexual offending, use of threats or weapons, male victim, and child victim. In addition, whereas the factor of JSO age was not included in Worling and Långström's review, McCann and Lussier found that this factor was in fact predictive of future sexual offending (i.e., that older age was associated with increased likelihood of reoffending).

In sum, the literature regarding risk factors for sexual recidivism among JSOs remains conflicted. Although some factors classified as supported by Worling and Långström (2006) were also found to be predictive of sexual recidivism in the metaanalysis by McCann and Lussier (2008), neither of these papers noted other factors found by Heilbrun, Lee, and Cottle (2005) to be predictive of sexually reoffending (i.e., noncontact offences). Further, a number of risk factors classified by Worling and Långström as unlikely were found to be predictive in the meta-analysis by McCann and Lussier. Similar inconsistencies are reflected in the findings of individual studies (e.g., Rasmussen, 1999; Smith \& Monastersky, 1986), which, as noted above, are also characterized by problems such as brief follow-up periods (e.g., Kahn \& Chambers, 
1991; Prentky et al., 2000), small sample sizes (e.g., Boyd, 1994; Miner, 2002), unclear reliability (e.g., Allan et al., 2003; Smith \& Monastersky, 1986), and the absence of a systematic, theoretically and empirically-based framework to inform the selection of risk factors (e.g., Nisbet et al., 2004; Rasmussen, 1999).

These issues and conflicted findings point to the need for more individual studies regarding risk factors for juvenile sexual recidivism. Such studies are necessary in order to address pertinent methodological issues and to provide a sound basis for further metaanalyses. This need for further individual studies has also been strongly emphasized by authors of meta-analyses (e.g., McCann \& Lussier, 2008; Worling \& Långström, 2006).

Within the context of these individual studies, there is also a need to examine the relationship between risk factors for nonsexual reoffending and the outcome of nonsexual recidivism among JSOs. There is an extensive literature on risk factors for nonsexual reoffending among general adolescent offender populations (e.g., Farrington, 2002) that has resulted in the identification of risk factors such as impulsivity and antisocial attitudes (e.g., Case \& Haines, 2007). However, despite high rates of nonsexual recidivism among JSOs (Caldwell, 2010), little research has been intended to examine whether these risk factors can be generalized from youth who have not sexually offended to JSOs.

\section{Protective Factors for Recidivism}

Although the majority of offending research has thus far focused on risk factors that increase likelihood of recidivism, there is burgeoning recognition of the need to investigate protective factors that may decrease likelihood of recidivism (Farrington, 2007). As yet, no studies have examined protective factors for sexual recidivism among JSOs. One measurement scale has been developed (Protective Factors Scale; Bremer, 2006), but there are no published data on the reliability or validity of this instrument.

The existing literature on protective factors for nonsexual recidivism has been criticized on a number of grounds. In particular, there has been definitional inconsistency with regard to whether protective factors are conceptualized as "mirror images" of risk factors or separate concepts unto themselves (e.g., Luthar \& McMahon, 1996). Stated differently, if substance abuse is considered to be a risk factor, there is some question as to whether absence of substance abuse constitutes a protective factor or whether such protective factors are distinct entities (Borum et al., 2006). Additional problems include inconsistency in examining direct versus moderating effects of protective factors, variable outcome measures, and failure to replicate results (Tolan, 2000). The validity of the Structured Assessment of Violence Risk in Youth (SAVRY; Borum et al., 2006) for assessing protective factors for nonsexual recidivism (e.g., prosocial involvement; strong attachments and bonds) has been supported by several recent studies of general adolescent offender populations (e.g., Lodewijks et al., 2010; Rennie \& Dolan, 2010), but it is clear that further research in this area is needed.

This need extends especially to JSOs and to protective factors for sexual recidivism in light of the aforementioned dearth of relevant studies. Such research is 
critical in order to improve the accuracy of risk assessment and to inform treatment interventions (Rogers, 2000), especially given that protective factors such as engagement in employment/education and strong attachments to prosocial others (Borum et al., 2006) have also been noted as critical to successful desistance from offending (Ward \& Laws, 2010). Moreover, given typological differences between JSOs and general adolescent offenders (Seto \& Lalumière, 2010), it is important to identify whether protective factors are consistent across both groups or whether there may be distinct protective factors that apply to JSOs in particular.

\section{The Present Study}

In light of these research needs, the purpose of the present study was to investigate the relationship of risk and protective factors to sexual and nonsexual recidivism among a sample of JSOs. Risk factors were selected based on the review by Worling and Långström (2006) and prior meta-analytic findings (Heilbrun, Lee, \& Cottle, 2005; McCann \& Lussier, 2008). Potential protective factors were selected based on the violence risk assessment literature (Borum, Bartel, \& Forth, 2006) given an absence of any studies examining protective factors for sexual offending specifically. Consistent with prior research using the SAVRY (Borum et al., 2006), we treated protective factors as positive and distinct (i.e., not simply the absence of risk factors). We aimed to improve upon methodological limitations in prior research by a) selecting risk factors based on prior theoretical and empirical frameworks (Heilbrun, Lee, \& Cottle, 2005; McCann \& Lussier, 2008; Worling \& Långström, 2006), b) examining a comprehensive set of risk factors, including factors that may or may not have relationships to sexual reoffending (Worling \& Långström, 2006), c) using a systematic approach to measure risk and protective factors (i.e., validated risk assessment tools, including the SAVRY), d) testing both direct and moderating effects of protective factors, and e) reporting interrater reliability for coding of risk and protective factors.

This line of research is important not only to expand the limited, conflicted base of knowledge concerning risk and protective factors for adolescent sexual offending (i.e., in regard to aforementioned methodological problems and inconsistencies with respect to risk factors examined), but also to inform clinical practice in which these factors play a critical part. For example, research regarding risk factors is needed to guide the development of risk tools for predicting sexual reoffending, particularly in light of conflicting findings regarding the psychometric properties of these measures (e.g., Martinez et al., 2007; Caldwell et al., 2008). Such knowledge could also be used to inform treatment strategies that are tailored to youths' specific risk factors and thereby mitigate their likelihood of reoffending (e.g., Andrews \& Bonta, 2010).

\section{Method}

\section{Participants}

Participants were 193 male adolescents admitted to a residential sex offending treatment program in a medium-sized American city from 1992 to 2005. The characteristics of this sample were previously described in Viljoen et al. (2009); readers are referred to this paper for detailed information regarding participants. 
Participants' mean age at admission was $15.26(\mathrm{SD}=1.54)$. The majority of youths were non-Hispanic Caucasian (82.9\%, $n=160)$, followed by African American (8.3\%, $n=16)$, Hispanic (4.7\%, $n=9)$, and American Indian/Alaskan Native $(1.6 \%, n=$ $3)$. Five youths (2.6\%) were of mixed race/ethnicity. Approximately half of youth had prior charges for sexual $(51.3 \%, n=99)$ and nonsexual offenses $(43 \%, n=83)$. In total, youth had a mean of 1.52 prior sexual charges $(S D=1.33)$ and a mean of 1.59 prior nonsexual charges $(S D=2.81)$. For the purposes of follow-up after treatment, participants had been discharged from the program for at least 250 days prior to data collection.

\section{Measures}

Risk and protective factors for sexual offending. Risk and protective factors for sexual offending were selected based on empirically informed frameworks and prior research findings. Specifically, we tested all risk factors for sexual reoffending identified in Worling and Långström's (2006) review and the meta-analyses conducted by Heilbrun et al. (2005) and McCann and Lussier (2008). With regard to protective factors, we examined those included on the Structured Assessment of Violence Risk in Youth (SAVRY; Borum, Bartel, \& Forth, 2006) due to the strong body of evidence supporting its psychometric properties (e.g., Olver et al., 2009; Welsh et al., 2008). However, these studies relate to general offending rather than to sexual offending specifically, and the SAVRY was used in this study because there is no empirically based guidance concerning protective factors among JSOs. All risk and protective factors examined, and the measures used to assess them, are listed in Tables 1 and 2.

Risk and protective factors were assessed primarily through the use of risk assessment instruments in order to have a clear, systematic strategy for measuring risk factors and to facilitate determination of interrater reliability. However, it should be noted that these measures were used to assess individual risk factors and were not scored in their aggregate form. The psychometric properties of these tools in their aggregate form were investigated in previous studies (Viljoen et al., 2008; 2009) and will not be repeated here. Briefly, the Estimate of Risk of Adolescent Sexual Offence Recidivism (ERASOR; Worling \& Curwen, 2001) consists of 25 risk factors for sexual reoffending that may be rated as present, possibly or partially present, not present, or unknown. The Juvenile Sex Offender Assessment Protocol II (J-SOAP-II; Prentky \& Righthand, 2003) consists of 28 risk factors for sexual reoffending and general delinquency that are scored on a 3-point scale, with higher scores representing greater risk. The Protective Factors scale of the SAVRY (Borum et al., 2006) consists of protective factors for violent offending that are scored on an absent or present basis.

In cases where risk factors identified in previous research (e.g., Heilbrun et al., 2005) were not included on risk assessment instruments (e.g., exhibitionistic index offence), file information was used. For the purposes of this study, risk factors were grouped into the categories of historical/static factors (e.g., prior criminal sanctions for sexual offending), victim-related factors (e.g., male victim), offence-related factors (e.g., penetrative offence), attitudes/beliefs (e.g., deviant sexual interest), social/contextual factors (e.g., social isolation), and interpersonal/behavioral factors (e.g., impulsivity). 
Similar categorizations are used on risk assessment measures (e.g., risk factors on the ERASOR are grouped into five categories, including "Sexual Interests, Attitudes, and Behaviors" and "Historical Sexual Assaults").

Risk and protective factors for nonsexual reoffending. Risk factors for nonsexual reoffending were selected based on prior empirical findings; specifically, the meta-analysis conducted by Cottle, Lee, and Heilbrun (2001). These risk factors and the measures used to assess them are listed in Tables 3 and 4 . As in the case of risk factors for sexual reoffending, well-validated risk assessment measures were used to evaluate risk factors whenever possible in order to adhere to a systematic measurement framework and to facilitate determination of reliability. Briefly, the SAVRY risk scales (Borum et al., 2006) include 24 risk factors for violence that are each scored on a 3-point scale. The Youth Level of Service/Case Management Inventory (YLS/CMI; Hoge et al., 2002) consists of 42 items relevant to juvenile offenders' risks and needs. Items are scored on an absent or present basis. Again, readers interested in the psychometric properties of these instruments in their aggregate form are referred to previous studies (Viljoen et al., 2008; 2009).

In cases where risk factors identified by Cottle et al. (2001) were not included on risk assessment instruments (e.g., out-of-home placement), file information was used. Operationalization and coding of these risk factors was generally straightforward (e.g., coding the risk factor genital penetrative offence simply involved examining file data regarding the index offence and rating, on a dichotomous basis, whether or not it was a genital penetrative offence). For the purposes of this study, risk factors for nonsexual reoffending were divided into the following categories: demographic characteristics (e.g., youth age), offense history (e.g., prior convictions for nonsexual offences), family/social factors (e.g., peer delinquency), and clinical factors (e.g., substance abuse). Protective factors were selected based on the SAVRY given its strong psychometric properties for assessing risk for nonsexual violence.

Recidivism. To evaluate sexual and nonsexual offending after discharge, youths' statewide juvenile justice and adult criminal records were obtained through law enforcement and probation sources as well as by reviewing subsequent treatment records. To ensure blind review, recidivism records were obtained following completion of file coding. Consistent with prior research (e.g., Gretton et al., 2004), nonsexual offenses were divided into violent offenses (i.e., violent felonies and violent misdemeanors) and nonviolent offenses (i.e., property felonies).

\section{Procedure}

Four graduate students in clinical forensic psychology coded risk and protective factors for each participant based on comprehensive file information. Prior to commencing coding, all raters received extensive training on the measures used to assess risk and protective factors. Training included didactic sessions, assigned readings, and the completion of five practice cases using actual case files.

Files were approximately 600 pages in length. They typically included psychiatric 
assessments, psychological assessments (which included a comprehensive battery of tests administered at intake and every 3 months), nursing records, medical examination information, social work reports, teacher assessments, school records, treatment plans, progress notes, physician orders, and correspondence with courts (e.g., arrest records) and other treatment providers.

Risk factors were coded based on the entire file. Because a number of dynamic variables were examined, files were coded based on information available at discharge (i.e., rather than admission). All coding was conducted blind to youths' subsequent charges and convictions.

In order to determine whether youth committed sexual or nonsexual offences following treatment, law enforcement and probation records were examined. On average, youth spent 399.73 days in the treatment program $(S D=250.00)$ and were followed for an average of 7.24 years following discharge $(S D=3.97$; range $=0.59-13.56$; median $=$ 7.58).

\section{Data Analysis}

For continuous variables (e.g., youth age), Pearson bivariate correlations were calculated. For dichotomous variables (e.g., whether the index offence was a penetrative sexual assault), phi coefficients were calculated. For ordinal variables (e.g., negative peer associations), Spearman bivariate correlation coefficients were calculated (Cohen, Cohen, West, \& Aiken, 2003).

\section{Results}

\section{Interrater Reliability}

Risk and protective factors for sexual reoffending. To assess interrater reliability for risk and protective factors measured on a 3-point scale, we calculated intraclass correlation coefficients using a two-way random effects model with consistency agreement (McGraw \& Wong, 1996). To assess reliability for risk and protective factors measured dichotomously, we calculated kappa coefficients (Cohen, 1960). The results of these analyses are presented in Tables 1 and 2.

Most ICCs had values between .40 and .94 , which fall in the fair to excellent range according to the classification system used by Cicchetti \& Sparrow (1981). Likewise, kappa values ranged from .40 to .56, which fall in the fair to moderate range according to the classification system used by Landis and Koch (1977). A number of risk factors had perfect interrater reliability (e.g., multiple victims, genital penetrative offence, anal penetrative offence, exhibitionism, and obscene phone calls). However, the risk factor of having a stranger victim had an ICC of .30, which is considered poor. As such, results relating to this variable should be interpreted cautiously.

Risk and protective factors for nonsexual reoffending. As in the case of sexual reoffending, ICCs were calculated for factors measured on a continuous and ordinal basis and kappas were calculated for factors measured dichotomously (see Tables 3 and 4). The 
majority of these values fell within the good to excellent range, and age at first nonsexual offence had perfect interrater reliability. However, the ICC for the poor use of leisure time risk factor was .11, which is considered poor. Hence, results relating to this factor should be interpreted cautiously.

\section{Relationship between Risk and Protective Factors and Sexual Recidivism}

Sixteen youths (8.3\%) sexually offended post-discharge (i.e., committed a sexual felony). Among all risk factors examined, only opportunities to reoffend was significantly associated with sexual recidivism (see Table 5). No protective factors examined were significantly associated with sexual reoffending. Notably, however, power to detect significant differences was limited due to the low base rate of sexual offending.

Given that no significant findings were obtained by testing direct effects of protective factors, we investigated the possibility that they may have moderating effects (e.g., Lodewijks et al., 2010). Stated differently, we tested whether protective factors had different relationships with sexual recidivism based on the youth's level of risk.

Consistent with Worling et al. (in press), we classified youths’ risk levels using their total ERASOR scores. Specifically, youths scoring 1 standard deviation above the mean or higher were classified as High risk. The $50^{\text {th }}$ percentile was used to differentiate Low from Moderate risk, as using 1 standard deviation below the mean would result in a large number of youths being classified as Moderate. Applied to this sample, ERASOR total scores of 0-24 were categorized as Low, 25-31 were categorized as Moderate, and total scores of 32 or higher were classified as High.

The results of these analyses are presented in Table 6. When divided among youths' risk levels, no protective factors examined had any significant associations with sexual recidivism. There were no significant differences between Low, Moderate, and High risk groups with respect to correlations between protective factors and sexual recidivism.

\section{Relationship between Risk and Protective Factors and Nonsexual Recidivism}

During the follow-up period, twenty-seven youths (14\%) committed a nonsexual violent offense and 39 youths (20\%) committed a nonsexual nonviolent offense (e.g., vandalism). The relationships between these outcomes and risk factors for nonsexual reoffending are listed in Table 7 . Number of prior charges and prior convictions for nonsexual offending were both associated with violent and nonviolent recidivism. Violent recidivism was associated with peer delinquency and age at first nonsexual offence (i.e., younger age at first nonsexual offence). Among protective factors, strong attachments and bonds was negatively associated with nonviolent recidivism.

\section{Discussion}

The present study was intended to investigate the relationship of risk and protective factors to sexual and nonsexual recidivism among a sample of JSOs in a 
residential treatment program. We also strove to improve upon methodological limitations of prior research by choosing risk factors based on prior empirical findings, examining a comprehensive set of risk factors, using systematic measurement approaches, and reporting interrater reliability. Our goals in conducting this research were to inform the limited knowledge base regarding risk and protective factors for offending among JSOs as well as to shed light on whether a) risk and protective factors for sexual reoffending are unique and overlapping with risk factors for nonsexual reoffending, and b) risk and protective factors for nonsexual reoffending that have been widely researched among general adolescent offender populations (e.g., Farrington, 2002) may be generalized to JSOs.

In regard to sexual reoffending, our findings indicated that (1) only opportunities to reoffend was associated with sexual recidivism and that (2) no protective factors examined were associated with sexual recidivism. In regard to nonsexual reoffending, our findings indicated that several risk factors identified in previous research were associated with nonsexual violent and nonviolent recidivism (e.g., peer delinquency), and that strong attachments and bonds served as a protective factor against nonviolent recidivism. These findings, and corresponding suggestions for further research, are discussed below.

\section{Primary Findings: Sexual Reoffending}

Consistent with Worling and Långström’s (2006) review of supported, promising, possible, and unlikely risk factors for sexual recidivism, no unlikely risk factors were associated with sexual reoffending. For example, although a history of sexual abuse is commonly perceived to be a risk factor (e.g., Mallie et al., 2011), it was not significantly related to sexual recidivism. However, no supported, promising, or possible risk factors were associated with sexual recidivism either, with the exception of opportunities to reoffend. None of the factors found by McCann and Lussier (2008) to be predictive of sexual reoffending, such as age of the youth and deviant sexual interests, were associated with sexual recidivism in this study.

There are several possible explanations for a lack of many significant findings. First, comparable to other research (e.g., Waite et al., 2005), there was a low base rate of sexual recidivism in the present study. Given that low base rates reduce the accuracy of prediction methods (Caldwell, 2010), this may have hampered our ability to detect significant relationships. Secondly, it is possible that the participants in this study differed from other participants in studies of adolescent sexual reoffending, particularly in terms of their admittance to a residential treatment program. For example, Allan et al. (2003) and Långström (2002) reported higher base rates of reoffending among youth not admitted to residential treatment. It is possible, for instance, that the treatment program in this study was effective or that risk management plans were put into place such that youths developed skills and strategies to manage their risk factors. Thirdly, the follow-up period was quite long, and it is possible that some risk factors may have changed during this period. Risk is dynamic, particularly in adolescence (e.g., Grisso, 1998), and subject to change over time. Finally, the lack of consistency between our results and previous research could also simply be indicative of the generally conflicted nature of the existing literature regarding risk factors for sexual recidivism among JSOs. 
It is important to note, however, that our failure to observe many significant relationships between sexual recidivism and risk factors does not necessarily reflect poorly on the risk assessment instruments used to measure these factors. In particular, such tools are meant to be used in an aggregate manner and to be based on a cumulative model of risk. It has generally been noted that relationships between individual risk factors and recidivism tend to be small, and therefore that any evaluation of risk should involve consideration of a range of risk factors and a combination of these factors into an overall summary determination of risk (Hanson \& Morton-Bourgon, 2009).

No protective factors examined were significantly associated with sexual recidivism. However, these factors protect against general violence rather than sexual reoffending. Hence, our findings suggest that there may be unique, different factors that protect against sexual reoffending specifically. Results of a recent meta-analysis (Seto \& Lalumière, 2010) suggest that there are important typological differences between JSOs and general adolescent offenders, with JSOs evidencing higher levels of problems such as social isolation, anxiety, and low self-esteem. Thus, it may be the case that protective factors corresponding to the particular difficulties faced by JSOs may be more meaningful for this population. For instance, results of a study on sexual aggression among community adolescents (Borowsky et al., 1997) indicate that connectedness with friends and adults in the community protected against sexually aggressive behaviour. This social connectedness could be seen as a protective factor corresponding to the risk factor of social isolation observed by Seto \& Lalumière, although the populations in these two studies differ. Further research should be undertaken to investigate a variety of potential protective factors among JSOs in order to better elucidate the possibility of distinct protective factors corresponding to the distinct risk factors present in this population.

\section{Primary Findings: Nonsexual Reoffending}

Consistent with many prior studies (e.g., Allan et al., 2003; Caldwell, 2010; Waite et al., 2005), rates of nonsexual recidivism were higher than rates of sexual recidivism in this study and several risk factors were associated with nonsexual recidivism. Although only one risk factor for sexual offending (opportunities to reoffend) was associated with sexual recidivism, we found that several risk factors for nonsexual reoffending were in fact related to nonsexual recidivism. In accordance with the meta-analysis conducted by Cottle, Lee, and Heilbrun (2001), these factors included prior nonsexual offending, age at first offense, and peer delinquency. Furthermore, we found that the protective factor of strong attachments and bonds was negatively associated with nonviolent nonsexual recidivism. These results are in agreement with more recent research (e.g., Olver et al., 2009) supporting the predictive validity of such risk factors, and suggest that these factors may generalize from a general adolescent offender population to JSOs. Our findings are also consistent with arguments that JSOs are not specific in their sexual offending (Caldwell, 2002). 


\section{Limitations and Future Directions}

The results of the present study should be considered in light of its limitations. First, consistent with other studies on risk factors for adolescent sexual reoffending (e.g., Allan et al., 2003), this study was retrospective and relied on file information. This approach allowed us to obtain a larger sample and longer follow-up period than if we had conducted a truly prospective study. However, there is a need for further prospective research incorporating both file reviews and face-to-face contact with youths not only to better examine predictive relationships, but also to improve rating of risk factors requiring more clinical judgment (e.g., low victim empathy).

Secondly, our failure to obtain many significant findings may be due, in part, to a lack of power. Only 16 youths reoffended sexually, indicating that there were not enough sexual recidivism events in the present study to detect medium or small effect sizes (Cohen, 1992). However, low base rates of reoffending plague many studies in this area (e.g., Martinez et al., 2007; Parks \& Bard, 2006; Waite et al., 2005), and it has been observed that significant findings can be uncommon in the field of adolescent sexual offending (Caldwell, 2010). Even in prior meta-analyses with large sample sizes (e.g., McCann \& Lussier, 2008), the effect sizes obtained tend to be small (for example, the largest effect size found by McCann and Lussier was .28 for having a stranger victim). This suggests that although low power and non-significant findings may be salient problems in individual studies, there is still an important need for these studies in order to provide a basis for further meta-analyses. Indeed, authors of meta-analyses have also emphasized the necessity for such studies (McCann \& Lussier, 2008; Worling \& Långström, 2006). As this research emerges, it is also critical to note that failure to obtain significant findings should not deter investigators from publishing their work. Despite substantial publication bias (Rosenthal, 1979), it is important for researchers with null results to disseminate their findings in order to advance the field.

A third limitation of the present study is that official records were used to assess reoffending. Clearly, such records are limited to those offenses that come to the attention of law enforcement and the courts, and may therefore underestimate true rates of reoffending. Sexual crimes, in particular, tend to be underreported (e.g., Furby et al., 1989). Future research should include a combination of official records, youth self-report, and other collateral reports (such as those of caregivers, teachers, or treatment providers).

In addition to these aforementioned research needs, there are many other avenues in the area of adolescent sexual reoffending that merit further study. For instance, amidst the field's predominant focus on male adolescent sexual offenders, it is important to also study females in order to determine whether there may be gender differences in risk factors. Secondly, dynamic assessment and reassessment should be investigated in order to elucidate differential predictive validity of risk determination at different time points. Thirdly, as noted above, protective factors should be studied further in light of the possibility that there may be different protective factors for sexual versus nonsexual reoffending. Such research should include tests of competing models of protective factors, (i.e., whether they have direct effects or operate as moderators/buffers; Lodewijks et al., 2010). 
Finally, there is a need to study not only risk factors, but also risk management strategies. Shedding light on which treatment approaches are most effective in protecting against reoffending is critically important for rehabilitating offenders and reducing the likelihood of further victims. Given that our findings indicated that the risk factor opportunities to reoffend was associated with sexual recidivism, it is possible that this area warrants increased attention. Opportunities to reoffend is a dynamic risk factor coded based on whether the adolescent presently or in the next 6 months will have access to an environment which supports reoffending, as evidenced by such factors as unsupervised access to potential victims, poor monitoring of the adolescent's whereabouts, and proximity to adults who are unaware of the adolescent's risk factors, engage in denial, or blame the victim (Worling \& Curwen, 2001). Hence, embedded in this factor are a number of relatively concrete management strategies and/or treatment targets that could be implemented by clinicians (e.g., ensuring supervision when the youth is in proximity to potential victims) and studied further.

\section{Conclusions}

Although research on risk factors for nonsexual recidivism has led to considerable advances in assessment approaches over the last decade, identification of risk factors for sexual recidivism has proven far more difficult. Clinicians' abilities to evaluate the likelihood that an adolescent will engage in such behavior are hampered considerably by a lack of studies supporting these risk factors as well as instruments intended to assess them. However, punitive laws and policies based on assumptions about risk are being implemented at a speed that is clearly outpacing the progress of research. Thus, there are imperative needs to reexamine such laws as well as to conduct further research on risk and protective factors for sexual offending among adolescents in order to inform evidence-based assessment and treatment strategies. 


\section{References}

Allan, A., Allan., M., Marshall, P., \& Kraszlan, K. (2003). Recidivism among male juvenile sexual offenders in Western Australia. Psychiatry, Psychology, and Law, 10, 359-378.

Andrews, D. A., \& Bonta, J. (2010). Rehabilitating criminal justice policy and practice. Psychology, Public Policy, and Law, 16, 39-55.

Borowsky, I W., Hogan, M., \& Ireland, M. (1997). Adolescent sexual aggression: Risk and protective factors. Pediatrics, 100, 1-8.

Borum, R., Bartel, P., \& Forth, A. (2006). Structured Assessment for Violence Risk in Youth (SAVRY). Tampa, FL: Mental Health Institute, University of South Florida.

Borum, R., \& Verhhaagen, D. (2006). Assessing and managing violence risk in juveniles. New York: Guilford Press.

Bremer, J. (2006). Protective factors scale: Determining the level of intervention for youth with harming sexual behavior. In D. S. Prescott (Ed.), Risk assessment of youth who have sexually abused (pp. 195-221). Oklahoma City: Wood 'N' Barnes Publishing and Distribution.

Boyd, N. (1994). Predictors of recidivism in an adolescent sexual offenders' population. Unpublished doctoral dissertation, University of Madison-Wisconsin.

Burton, D. L. (2003). The relationship between sexual victimization and subsequent sexual abuse by male adolescents. Child and Adolescent Social Work Journal, 2, 277-296.

Caldwell, M. F. (2007). Sexual offense adjudication and sexual recidivism among juvenile offenders. Sexual Abuse: Journal of Research and Treatment, 19, 107113.

Caldwell, M. F. (2010). Study characteristics and recidivism base rates in juvenile sex offender recidivism. International Journal of Offender Therapy and Comparative Criminology, 54, 197-212.

Caldwell, M., Ziemke, M., \& Vitacco, M. (2008). An examination of the Sex Offender Registration and Notification Act as applied to juveniles: Evaluating the ability to predict sexual recidivism. Psychology, Public Policy, and the Law, 14, 89-114.

Case, S., \& Haines, K. (2007). Offending by young people: A further risk factor analysis. Security Journal, 20, 96-110.

Chu, C. M., \& Thomas, S. D. M. (2010). Adolescent sexual offenders: The relationship between typology and recidivism. Sexual Abuse: A Journal of Research and Treatment, 22, 218-233.

Cicchetti, D. V. \& Sparrow, S. S. (1981). Developing criteria for establishing interrater reliability of specific items: Applications to assessment of adaptive behavior. American Journal of Mental Deficiency, 86, 127-137.

Cohen, J. (1960). A coefficient of agreement for nominal scales. Educational and Psychological Measurement, 20, 37-46.

Cohen, J. (1992). A power primer. Psychological Bulletin, 112, 155-159.

Cohen, J., Cohen, P., West, S. G., \& Aiken, L. S. (2003). Applied multiple regression/correlation analysis for the behavioral sciences ( $3^{\text {rd }}$ ed.). Mahwah, NJ: Lawrence Erlbaum.

Cottle, C., Lee, R., \& Heilbrun, K. (2001). The prediction of criminal recidivism in juveniles: A meta-analysis. Criminal Justice and Behavior, 28,367-394. 
Farrington, D. P. (2002). Multiple risk factors for multiple problem violent boys. In R. R. Corrado, R. Roesch, S. D. Hart, \& J. K. Gierowski (Eds.), Multi-problem violent youth: A foundation for comparative research on needs, interventions, and outcomes (pp. 23-34). Amsterdam, North Holland: IOS Press.

Farrington, D. P. (2007). Advancing knowledge about desistance. Journal of Contemporary Criminal Justice, 23, 125-134.

Furby, L., Weinrott, M. R., Blackshaw, L. (1989). Sex offender recidivism: A review. Psychological Bulletin, 105, 3-30.

Gretton, H., Hare, R., \& Catchpole, R. (2004). Psychopathy and offending from adolescence to adulthood. Journal of Consulting and Clinical Psychology, 72, 636-645.

Grisso, T. (1998). Forensic evaluations of juveniles. Sarasota, FL: Professional Resource Exchange.

Hanson, R. K., \& Morton-Bourgon, K. (2009). The accuracy of recidivism risk assessment instruments for sexual offenders: A meta-analysis of 118 prediction studies. Psychological Assessment, 21, 1-21.

Heilbrun, K., Lee, R., \& Cottle, C. C. (2005). Risk factors and intervention outcomes: Meta-analyses of juvenile offending. In K. Heilbrun, N. E. Goldstein, \& R. Redding (Eds.), Juvenile delinquency: Prevention, assessment, and intervention (pp. 111-133). New York City, New York: Oxford University Press.

Hoge, R., Andrews, D. A., \& Leschied, A. (2002). Youth Level of Service / Case Management Inventory: YLS/CMI Manual. Toronto, Ontario, Canada: MultiHealth Systems.

Kahn, T., \& Chambers, H. (1991). Assessing re-offense risk with juvenile sexual offenders. Child Welfare, 70, 333-346.

Knight, R. A., \& Sims-Knight, J. E. (2003). Developmental antecedents of sexual coercion against women: testing of alternative hypotheses with structural equation modeling. In R. A. Prentky, E. S. Janus, \& M. Seto (Eds.), Sexual coercive behavior: Understanding and management (pp. 72-85). New York: New York Academy of Sciences.

Landis, J. R., \& Koch, G. G. (1977). The measurement of observer agreement for categorical data. Biometrics, 33, 159-174.

Långström, N. (2002). Long-term follow-up of criminal recidivism in young sex offenders: Temporal patterns and risk factors. Psychology, Crime, \& Law, 8, 4158.

Letourneau, E. J., \& Miner, M. H. (2005). Juvenile sex offenders: A case against the legal and clinical status quo. Sexual Abuse: Journal of Research and Treatment, 17, 293-312.

Lodewijks, H. P. B., de Ruiter, C., \& Doreleijers, T. A. H. (2010). The impact of protective factors in desistance from violent reoffending: A study in three samples of adolescent offenders. Journal of Interpersonal Violence, 25, 568-587.

Luthar, S. S., \& McMahon, T. J. (1996). Peer reputation among inner city adolescents: Structure and correlates. Journal of Research on Adolescence, 6, 581-603.

McCann, K., \& Lussier, P. (2008). Antisociality, sexual deviance, and sexual reoffending in juvenile sex offenders: A meta-analytical investigation. Youth Violence and Juvenile Justice, 6, 363-385. 
McGraw, K. O., \& Wong, S. P. (1996). Forming inferences about some intraclass correlation coefficients. Psychological Methods, 1, 30-46.

Mallie, A., Viljoen, J. L., Mordell, S., Spice, A., \& Roesch, R. (2011). Childhood abuse and adolescent sexual re-offending: A meta-analysis. Child and Youth Care Forum, 40, 401-417.

Mann, R. E., Hanson, R. K., \& Thornton, D. (2010). Assessing risk for recidivism: Some proposals on the nature of psychologically meaningful risk factors. Sexual Abuse: A Journal of Research and Treatment, 22, 191-217.

Martinez, R., Flores, J., \& Rosenfeld, B. (2007). Validity of the Juvenile Sex Offender Assessment Protocol-II (J-SOAP-II) in a sample of urban minority youth. Criminal Justice and Behavior, 34, 1284-1295.

Miner, M. (2002). Factors associated with recidivism in juveniles: An analysis of serious juvenile sex offenders. Journal of Research in Crime and Delinquency, 39, 421436.

Moffitt, T. E. (1993). Adolescence-limited and life-course-persistent antisocial behavior: A developmental taxonomy. Psychological Review, 100, 674-701.

Nisbet, I., Wilson, P., \& Smallbone, S. (2004). A prospective longitudinal study of sexual recidivism among adolescent sex offenders. Sexual Abuse: A Journal of Research and Treatment, 16, 223-234.

Olver, M. E., Stockdale, K. C., \& Wormith, S. J. (2009). Risk assessment with young offenders: A meta-analysis of three assessment measures. Criminal Justice and Behavior, 36, 329-353.

Prentky, R., Harris, B., Frizzell, K., \& Righthand, S. (2000). An actuarial procedure for assessing risk with juvenile sex offenders. Sexual Abuse: A Journal of Research and Treatment, 12, 71-93.

Prentky, R., \& Righthand, S. (2003). Juvenile Sex Offender Assessment Protocol II (JSOAP-II) manual. Washington, DC: U. S. Department of Justice, Office of Justice Programs, Office of Juvenile Justice and Delinquency Prevention.

Rasmussen, L. (1999). Factors related to recidivism among juvenile sexual offenders. Sexual Abuse: A Journal of Research and Treatment, 11, 69-85.

Rice, M. E., \& Harris, G. T. (2005). Comparing effect sizes in follow-up studies: ROC area, Cohen's d, and r. Law and Human Behavior, 29, 615-620.

Rogers, R. (2000). The uncritical acceptance of risk assessment in forensic practice. Law and Human Behavior, 24, 595-605.

Rosenthal, R. (1979). The file drawer problem and tolerance for null results. Psychological Bulletin, 86, 638-641.

Seto, M. C., \& Lalumière, M. L. (2010). What is so special about male adolescent sexual offending? A review and test of explanations through meta-analysis. Psychological Bulletin, 136, 526-575.

Sisk, C. L., \& Foster, D. (2004). The neural basis of puberty and adolescence. Nature Neuroscience, 7, 1040-1047.

Smith, W., \& Monastersky, C. (1986). Assessing juvenile sexual offenders’ risk for reoffending. Criminal Justice and Behavior, 13, 115-140.

Tolan, P. (2000). Youth Violence Prevention. Chicago: Institute of Juvenile Research, University of Illinois. 
Trivits, L. C., \& Reppucci, N. D. (2002). Application of Megan’s law to juveniles. American Psychologist, 57, 690-704.

Viljoen, J. L., Elkovitch, N., Scalora, M., \& Ullman, D. (2009). Assessment of reoffense risk in adolescents who have committed sexual offences: Predictive validity of the ERASOR, PCL:YV, YLS/CMI, and Static-99. Criminal Justice and Behaviour, 36, 981-1000.

Viljoen, J. L., Scalora, M., Cuadra, L., et al. (2008). Assessing risk for violence in adolescents who have sexually offended: A comparison of the J-SOAP-II, JSORRAT-II, and SAVRY. Criminal Justice and Behavior, 35, 5-23.

Waite, D., Keller, A., McGarvey, E., et al. (2005). Juvenile sex offender re-arrest rates for sexual, violent nonsexual and property crimes: A 10-year follow-up. Sexual Abuse: A Journal of Research and Treatment, 17, 313-331.

Ward, T., \& Laws, R. (2010). Desistance from sex offending: Motivating change, enriching practice. International Journal of Forensic Mental Health, 9, 11-23.

Welsh, J. L., Schmidt, F., McKinnon, L., et al. (2008). A comparative study of adolescent risk assessment instruments: Predictive and incremental validity. Assessment, 15, 104-116.

Worling, J. R., Bookalam, D., \& Litteljohn, A. (in press). Prospective validity of the Estimate of Risk of Adolescent Sexual Offense Recidivism (ERASOR). Sexual Abuse: A Journal of Research and Treatment.

Worling, J. R., \& Curwen, T. (2001). Estimate of Risk of Adolescent Sexual Offense Recidivism (Version 2.0). Toronto, Ontario: Ontario Ministry of Community and Social Services.

Worling, J., \& Långström, N. (2006). Risk of sexual recidivism in adolescents who offend sexually: Correlates and assessment. In H. E. Barbaree \& W. L. Marshall (Eds.), The juvenile sex offender ( $2^{\text {nd }}$ ed., pp. 219-247). New York City, New York: Guilford.

Zimring, F. E. (2004). An American Travesty: Legal responses to adolescent sexual offending. Chicago, Illinois: University of Chicago Press. 
Table 1

Sexual Recidivism Risk Factors, Measurement Strategies, and Interrater Reliability: Trichotomous and Continuous Scales

\begin{tabular}{|c|c|c|c|}
\hline Risk Factor & $\begin{array}{l}\text { Measurement } \\
\text { Strategy }\end{array}$ & Coding Scheme & $\begin{array}{l}\text { Intraclass } \\
\text { Correlation } \\
\text { Coefficient }\end{array}$ \\
\hline $\begin{array}{c}\text { Historical/Static Risk } \\
\text { Factors }\end{array}$ & & & \\
\hline $\begin{array}{l}\text { Prior Criminal Sanctions } \\
\text { for Sexual Offending }\end{array}$ & ERASOR & 3 point scale & .76 \\
\hline $\begin{array}{l}\text { History of Nonsexual } \\
\text { Offending }\end{array}$ & File information & Continuous & .94 \\
\hline $\begin{array}{l}\text { Youth's Own History of } \\
\text { Sexual Victimization }\end{array}$ & J-SOAP-II & 3 point scale & .94 \\
\hline $\begin{array}{l}\text { Age at Admission } \\
\text { Victim-Related Risk } \\
\text { Factors }\end{array}$ & File information & Continuous & 1.0 \\
\hline Multiple Victims & ERASOR & 3 point scale & 1.0 \\
\hline Stranger Victim & ERASOR & 3 point scale & .30 \\
\hline Male Victim & ERASOR & 3 point scale & .96 \\
\hline $\begin{array}{l}\text { Child Victim } \\
\text { Offence-Related Risk } \\
\text { Factors }\end{array}$ & ERASOR & 3 point scale & .40 \\
\hline $\begin{array}{l}\text { Threats, Violence, or } \\
\text { Weapons in Sexual }\end{array}$ & & 3 point scale & .58 \\
\hline $\begin{array}{l}\text { Offence } \\
\text { Attitude/Belief Risk } \\
\text { Factors }\end{array}$ & ERASOR & & \\
\hline Deviant Sexual Interest & ERASOR & 3 point scale & .67 \\
\hline $\begin{array}{l}\text { Attitudes Supportive of } \\
\text { Sexual Offending }\end{array}$ & ERASOR & 3 point scale & .79 \\
\hline Sexual Preoccupation & ERASOR & 3 point scale & .75 \\
\hline $\begin{array}{l}\text { Denial of Sexual } \\
\text { Offending }\end{array}$ & J-SOAP-II & 3 point scale & .80 \\
\hline $\begin{array}{l}\text { Low Victim Empathy } \\
\text { Social/Contextual Risk } \\
\text { Factors }\end{array}$ & J-SOAP-II & 3 point scale & .66 \\
\hline Social Isolation & ERASOR & 3 point scale & .63 \\
\hline $\begin{array}{l}\text { Uncompleted Offense- } \\
\text { Specific Treatment }\end{array}$ & ERASOR & 3 point scale & .93 \\
\hline $\begin{array}{l}\text { Problematic Parent- } \\
\text { Adolescent Relationship }\end{array}$ & ERASOR & 3 point scale & .94 \\
\hline $\begin{array}{l}\text { High-Stress Family } \\
\text { Environment }\end{array}$ & ERASOR & 3 point scale & .40 \\
\hline
\end{tabular}


Risk Factors 21

Negative Peer

ERASOR

3 point scale

.72

Associations

ERASOR

3 point scale

.70

Interpersonal/Behavioral

Risk Factors

Impulsivity

Antisocial Interpersonal

ERASOR

3 point scale

.68

Orientation

$\begin{array}{lll}\text { ERASOR } & 3 \text { point scale } & .94\end{array}$

Interpersonal Aggression

ERASOR

3 point scale

.40 
Table 2

Sexual Recidivism Risk and Protective Factors, Measurement Strategies, and Interrater Reliability: Dichotomous Scales

\begin{tabular}{|c|c|c|}
\hline Risk/Protective Factor & Measurement Strategy & Kappa \\
\hline \multicolumn{3}{|l|}{ Offence-Related Risk } \\
\hline Genital Penetrative Offence & File information & 1.0 \\
\hline Anal Penetrative Offence & File information & 1.0 \\
\hline Noncontact (Exhibitionism) & File information & 1.0 \\
\hline $\begin{array}{l}\text { Noncontact (Obscene phone } \\
\text { calls) }\end{array}$ & File information & 1.0 \\
\hline \multicolumn{3}{|l|}{ Protective Factors } \\
\hline Prosocial Involvement & SAVRY & .56 \\
\hline Strong Social Support & SAVRY & .47 \\
\hline $\begin{array}{l}\text { Strong Attachments and } \\
\text { Bonds }\end{array}$ & SAVRY & .54 \\
\hline $\begin{array}{l}\text { Positive Attitude Towards } \\
\text { Intervention and Authority }\end{array}$ & SAVRY & .53 \\
\hline $\begin{array}{l}\text { Strong Commitment to } \\
\text { School }\end{array}$ & SAVRY & .42 \\
\hline Resilient Personality Traits & SAVRY & .40 \\
\hline
\end{tabular}


Table 3

Nonsexual Recidivism Risk Factors, Measurement Strategies, and Interrater Reliability: Trichotomous and Continuous Scales

\begin{tabular}{|c|c|c|c|}
\hline Risk Factor & $\begin{array}{c}\text { Measurement } \\
\text { Strategy }\end{array}$ & Coding Scheme & $\begin{array}{l}\text { Intraclass } \\
\text { Correlation } \\
\text { Coefficient } \\
\end{array}$ \\
\hline \multicolumn{4}{|l|}{ Offending History } \\
\hline Previous Nonsexual & & Continuous & .94 \\
\hline Charges & File Information & & \\
\hline Previous Nonsexual & & Continuous & .94 \\
\hline Convictions & File Information & & \\
\hline Age at First & & Continuous & 1.0 \\
\hline $\begin{array}{c}\text { Nonsexual Offence } \\
\text { Family/Social } \\
\text { Characteristics }\end{array}$ & File Information & & \\
\hline Poor Use of Leisure & YLS/CMI & 3-item & .11 \\
\hline Time & & $\begin{array}{c}\text { Leisure/Recreation } \\
\text { Scale }\end{array}$ & \\
\hline Significant Current & YLS/CMI & 6-item Family & .80 \\
\hline Family Problems & & $\begin{array}{c}\text { Circumstances/Parenting } \\
\text { Scale }\end{array}$ & \\
\hline $\begin{array}{l}\text { Poor Parental } \\
\text { Management }\end{array}$ & SAVRY & 3 point scale & .68 \\
\hline $\begin{array}{l}\text { Peer Delinquency } \\
\text { Clinical Factors }\end{array}$ & SAVRY & 3 point scale & .83 \\
\hline Substance Abuse & SAVRY & 3 point scale & .81 \\
\hline Nonsevere & SAVRY & 3 point scale & .72 \\
\hline \multicolumn{4}{|l|}{ Pathology } \\
\hline Conduct Problems & J-SOAP-II & 3 point scale & .75 \\
\hline
\end{tabular}


Table 4

Nonsexual Recidivism Risk Factors, Measurement Strategy, and Interrater Reliability: Dichotomous Scales

\begin{tabular}{llr}
\multicolumn{1}{c}{ Risk Factor } & Measurement Strategy & Kapp \\
\hline \multicolumn{1}{c}{ Family/Social } & & \\
Characteristics & & .73 \\
History of Physical Abuse & File Information & .89 \\
History of Sexual Abuse & File Information & .81 \\
Abuse & File Information & .84 \\
History of Neglect & & .66 \\
Living with Both Parents & File Information & .85 \\
Out-of-Home Placement & File Information & .71 \\
History of Special & File Information & \\
Education & File Information &
\end{tabular}


Risk Factors 25

Table 5

Relationship of Risk and Protective Factors for Sexual Recidivism to Sexual Recidivism

Risk/Protective Factor Correlation with Sexual Recidivism

Historical/Static Factors

Prior Criminal Sanctions for Sexual

Offending

History of Nonsexual Offending

Youth's Own History of Sexual

Victimization

Age at Admission

Victim-Related Factors

Multiple Victims

.04

Male Victim

Child Victim

Offence-Related Factors

Threats, Violence, or Weapons in Sexual

Offence

Genital Penetrative Offence

Anal Penetrative Offence

Noncontact Offence (Exhibitionism)

Noncontact Offence (Obscene Phone

Calls)

\section{Attitude/Belief Factors}

Deviant Sexual Interest

Attitudes Supportive of Sexual

Offending

Sexual Preoccupation

Denial of Sexual Offending

Low Victim Empathy

$-.04$

\section{Social/Contextual Factors}

Social Isolation

Uncompleted Offense-Specific

Treatment

.12

Problematic Parent-Adolescent

Relationship

High-Stress Family Environment

.08

Negative Peer Associations

Environment Supporting Reoffending

Interpersonal/Behavioral Factors

Impulsivity

Antisocial Interpersonal Orientation

Interpersonal Aggression

Protective Factors

Prosocial Involvement 
Risk Factors 26

Strong Social Support

$-.06$

Strong Attachments and Bonds

Positive Attitude Towards Intervention

and Authority

Strong Commitment to School

.01

Resilient Personality Traits

$-.01$

Note. $*=p<.05$. 
Table 6

Correlations between Protective Factors and Sexual Recidivism, by Risk Level Risk Protective Factor

\begin{tabular}{lcccccc}
\multicolumn{1}{c}{ Level } & \multicolumn{1}{c}{$\begin{array}{l}\text { Prosocial } \\
\text { Involvement }\end{array}$} & $\begin{array}{c}\text { Social } \\
\text { Support }\end{array}$ & $\begin{array}{c}\text { Attachments } \\
\text { and Bonds }\end{array}$ & $\begin{array}{c}\text { Positive } \\
\text { Attitude/Intervention }\end{array}$ & $\begin{array}{c}\text { School } \\
\text { Commitment }\end{array}$ & $\begin{array}{c}\text { Resilient } \\
\text { Personality }\end{array}$ \\
\hline Low & .06 & -.13 & .05 & .10 & .08 & -.05 \\
Moderate & .11 & -.07 & .05 & -.01 & -.03 & -.12 \\
High & .13 & -.01 & .04 & -.26 & -.16 & .10
\end{tabular}

Note. No correlations between protective factors and sexual recidivism were significant. 
Table 7

Relationship of Risk Factors for Nonsexual Recidivism to Violent and Nonviolent Recidivism

Risk Factor Violent Recidivism Nonviolent Recidivism

\section{Offending History}

Previous Nonsexual Charges

Previous Nonsexual

Convictions

Age at First Nonsexual

Offence

\section{Family/Social}

Characteristics

History of Physical Abuse

History of Sexual Abuse

History of Emotional Abuse

History of Neglect

Living with Both Parents

Out-of-Home Placement

Significant Current Family

Problems

Poor Parental Management

Peer Delinquency

History of Special Education

Clinical Factors

Substance Abuse

Nonsevere Pathology

Conduct Problems

Protective Factors

Prosocial Involvement

Strong Social Support

Strong Attachments and

Bonds

Positive Attitude Towards

Intervention and Authority

Strong Commitment to

School

Resilient Personality Traits

Note. $*=p<.05, * *=p<.01$.
$.28 * *$

$.24 * *$

$.18 * *$

$.26 * *$

$.26 * *$
$-.12$

$-.06$

$-.10$

$-.11$

.05

$-.03$

.05

.06

$.19 *$

.12

$-.10$

.09

.08

.05

.03

.02

.05

.07

.06
$-.07$

$-.07$

$-.06$

$-.01$

.06

$-.07$

.02

.02

.13

.03

$-.06$

$-.09$

.14

.01

.05

$-.18^{* *}$

.08

$-.09$

.02 